DOI: $10.12957 /$ demetra.2016.15470

\title{
Jamie Oliver e a revolução dos alimentos: as contribuições de um cozinheiro para pensar educação alimentar e nutricional
}

\author{
Jamie Oliver and the food revolution: the contributions of a cook to think about food and \\ nutrition education
}

Eneida Laís de0liveira Sousal Michelle Cristine Medeiros da Silva²

Célia Márcia Medeiros de Morais'

Vera Lúcia Xavier Pinto?

1 Universidade Federal do Rio Grande do Norte, Departamento de Nutrição, Curso de Nutrição. Natal-RN, Brasil.

${ }^{2}$ Universidade Federal de Campina Grande, Unidade Acadêmica de Saúde, Curso de Nutrição. Cuité-PB, Brasil.

Correspondência / Correspondence Eneida Laís deOliveira Sousa

E-mail: eneidalasousa@gmail.com

\section{Resumo}

A culinária pode ser utilizada como ferramenta para promoção de hábitos alimentares saudáveis. Desse modo, o trabalho objetivou conhecer os eixos que integram a prática profissional de Jamie Oliver enquanto cozinheiro que empreende educação alimentar. Foi realizada uma pesquisa qualitativa considerando imagens e vídeos divulgados, respectivamente, no Instagram ${ }^{\circledR}$ e em seu canal no Youtube $\AA$, o Foodtube $\AA$, durante o mês de abril de 2013. As imagens paradas foram avaliadas pela Análise Semiológica, com elaboração de dois tipos de comentários. Os vídeos foram traduzidos e posteriormente submetidos à metodologia de Análise por Imagem em Movimento. Elaborou-se comentários em três níveis. Foram extraídas palavras-chave tanto das imagens quanto dos vídeos, as quais passaram por reagrupação para elucidar as categorias, que são: "cozinhar é um ato político", "cozinhar é um ato contemporâneo", "cozinhar expressa processos de singularização". O teor político se deve à busca do bem comum por meio da alimentação. A contemporaneidade se traduz na aproximação e, ao mesmo tempo, no afastamento do ato de comer e do sistema que o permeia no tempo presente. Já a singularização é observada essencialmente nos novos conceitos divulgados pelo cozinheiro ao fazer educação alimentar. Conclui-se que para Oliver a comida é um patrimônio. A alimentação contemporânea acompanha as mudanças na sociedade, dialogando com as mesmas. Reitera-se a importância de a educação alimentar e nutricional convidar outros profissionais a seu campo de abrangência.

Palavras-chave: Educação alimentar e nutricional. Culinária. Promoção da saúde. 


\section{Abstract}

The cooking can be used as a tool to promote healthy eating habits. Therefore, the study focused on the axes which are part of the professional practice of Jamie Oliver as a cook who undertakes food education. A qualitative research was carried out considering images and videos published respectively in his Instagram ${ }^{\circledR}$ and his channel on YouTube $\AA^{\circledR}$, the Food tube ${ }^{\circledR}$, during the month of April 2013. The pictures were evaluated by the Semiological Analysis with development of two types of reviews. The videos were translated and then submitted to the Analysis Methodology for Moving Image. Three levels of comments were elaborated. Keywords were extracted from both images as well as the videos, which have been regrouped to clarify the categories, which are: "Cooking is a political act", "cooking is a contemporary act", "cooking expresses singularity processes. "The political content is due to the pursuit of the common through food. The political content is due to the pursuit of the common through food. The contemporary is translated into the approach and at the same time, the distancing from the act of eating and from the system which permeates it at the present time. Besides, the singling is observed essentially in the new concepts disclosed by the cook when he started the revolution of food education. It is concluded that for Oliver that food is a heritage. The contemporary food follows the changes in society, interacting with them. It is desired that this study can reaffirm the importance of food and nutrition education as well as engage other professionals to this field.

Key words: Food and Nutrition education. Cooking. Health Promotion.

\section{Introdução}

Sendo a culinária um sistema de uma cultura e um enunciado histórico é importante que algumas das suas produções sejam consideradas fontes de compreensão dos modos de comer de um grupo. Nesse sentido, a Educação Alimentar e Nutricional requer uma abordagem integrada que reconheça as práticas alimentares como resultantes de tais fatores além da disponibilidade e acesso aos alimentos. ${ }^{1}$

Para Educação Alimentar e Nutricional gosto se discute. Atualmente, uma das formas de fazer isso é por meio do incentivo à prática culinária: aprender a cozinhar, lidar com os alimentos em seu estado, plantar, ir à feira, colher. A ideia é que a culinária como prática venha a integrar um dos seus princípios defendido pelo Marco de referência de educação alimentar e nutricional para as 
políticas públicas ${ }^{3}$ lançado pelo Ministério do Desenvolvimento Social, em 2012, assim intitulado: Valorização da culinária enquanto prática emancipatória. Além disso, Diez-Garcia \& Castroª apontam para a ideia de que a manipulação do alimento, proporcionada pela culinária, facilita a reflexão e o exercício das dimensões sensoriais, cognitivas e simbólicas da alimentação.

Para avançar nesse princípio relativo à culinária proposto pelo Marco é necessário travar intenso diálogo com profissionais desse campo que demonstram preocupação em articular educação e alimentação. Um desses profissionais na atualidade é o inglês Jamie Oliver. Seu projeto é empreender uma revolução na alimentação, food revolution.$^{2-6}$ Oliver faz, assumidamente, Educação Alimentar ao contribuir para a transmissão das novas ideias e conceitos sobre a culinária e as relações que envolvem o ato de cozinhar e alimentar-se. ${ }^{6}$

A respeito da pesquisa qualitativa imagética, atualmente é notório o grande destaque à dimensão visual, principalmente em razão do advento da internet e da propagação da comunicação global, em virtude da hipermidiação, que consiste nas múltiplas dimensões da informação combinadas: texto, áudio e imagem. Ao longo da história da humanidade, a imagem mostrou-se um dos principais meios de comunicação. ${ }^{7}$ Segundo Sardelich, ${ }^{8}$ a distância que ainda existe entre a riqueza da experiência visual e a habilidade para esta observação oportuniza e cria a necessidade de converter a cultura visual em campo de estudo.

Os objetivos gerais deste trabalho são conhecer os eixos que integram a prática profissional de Jamie Oliver enquanto cozinheiro que empreende educação alimentar; indicar ideias que se refletem ou poderiam se refletir nas práticas de Educação Alimentar e Nutricional e destacar os projetos, formais e não formais, desenvolvidos por Jamie Oliver. Enquanto objetivo específico visa compreender que educação alimentar e nutricional requer reflexões e práticas para além da abordagem biomédica que caracteriza a Nutrição.

\section{Metodologia}

Para realizar a pesquisa qualitativa foram coletados dois tipos de elementos imagéticos divulgados ao longo de um mês: fotografias, no Instagram ${ }^{\circledR}$ oficial de Jamie Oliver (http:// instagram.com/jamieoliver) e vídeos, no seu canal próprio do Youtube® - o Foodtube®. Os dois tipos de arquivos foram armazenados digitalmente compondo o corpus da pesquisa. 
Imagem parada

As fotografias foram submetidas à Análise Semiológica, baseada na ideia de que as imagens são um sistema de signos. Consistiu em três etapas: (1) inicialmente, foram escolhidas as imagens a ser analisadas. Todas as fotos divulgadas durante o mês de abril do ano de 2013 foram incluídas; (2) em seguida, os elementos contidos nestas foram identificados, considerando seu sentido literal; (3) por fim, fez-se uma análise conotativa aplicando a cada elemento uma série de perguntas $(\mathrm{O}$ que tal elemento conota? Como os elementos se relacionam uns com os outros?). ${ }^{9}$ Paralelamente à referida análise, foram elaborados o comentário geral e o comentário a respeito da forma como os alimentos aparecem nas imagens. Em seguida, foram atribuídas as palavras-chave para cada uma das fotos.

\section{Análise de imagem em movimento}

Os vídeos, referentes ao mês de abril de 2013, foram traduzidos, transcritos e posteriormente analisados utilizando-se a metodologia de Análise por Imagem em Movimento, que originalmente compreende: ${ }^{10}$ (1) coleta de informações básicas sobre o vídeo (título em português, título original, ano, país, gênero, duração, tema); (2) transcrição do material (dimensão visual e dimensão verbal) e (3) estabelecimento e compreensão das relações entre esses elementos decompostos, ou seja, interpretação.

Para tal análise, realizou-se uma adaptação na metodologia em que foram inseridos comentários em três níveis. O primeiro deles consistiu em um comentário geral sobre os vídeos. O segundo, um comentário específico das referências alimentares presentes. No terceiro nível foi elaborado um comentário para cada vídeo, a partir da correlação entre suas dimensões verbal e visual. Em seguida, foram extraídas palavras-chave, considerando tais níveis.

\section{Palavras-chave}

As palavras-chave geradas pelas imagens paradas e em movimento foram reagrupadas em conjuntos em três níveis: (1) Conjugação de palavras iguais; (2) conjugação de palavras sinônimas e (3) conjugação dos elementos restantes em conceitos que abrangessem as reflexões sinalizadas pelas palavras. O fluxograma a seguir resume o processo de análise imagética. 


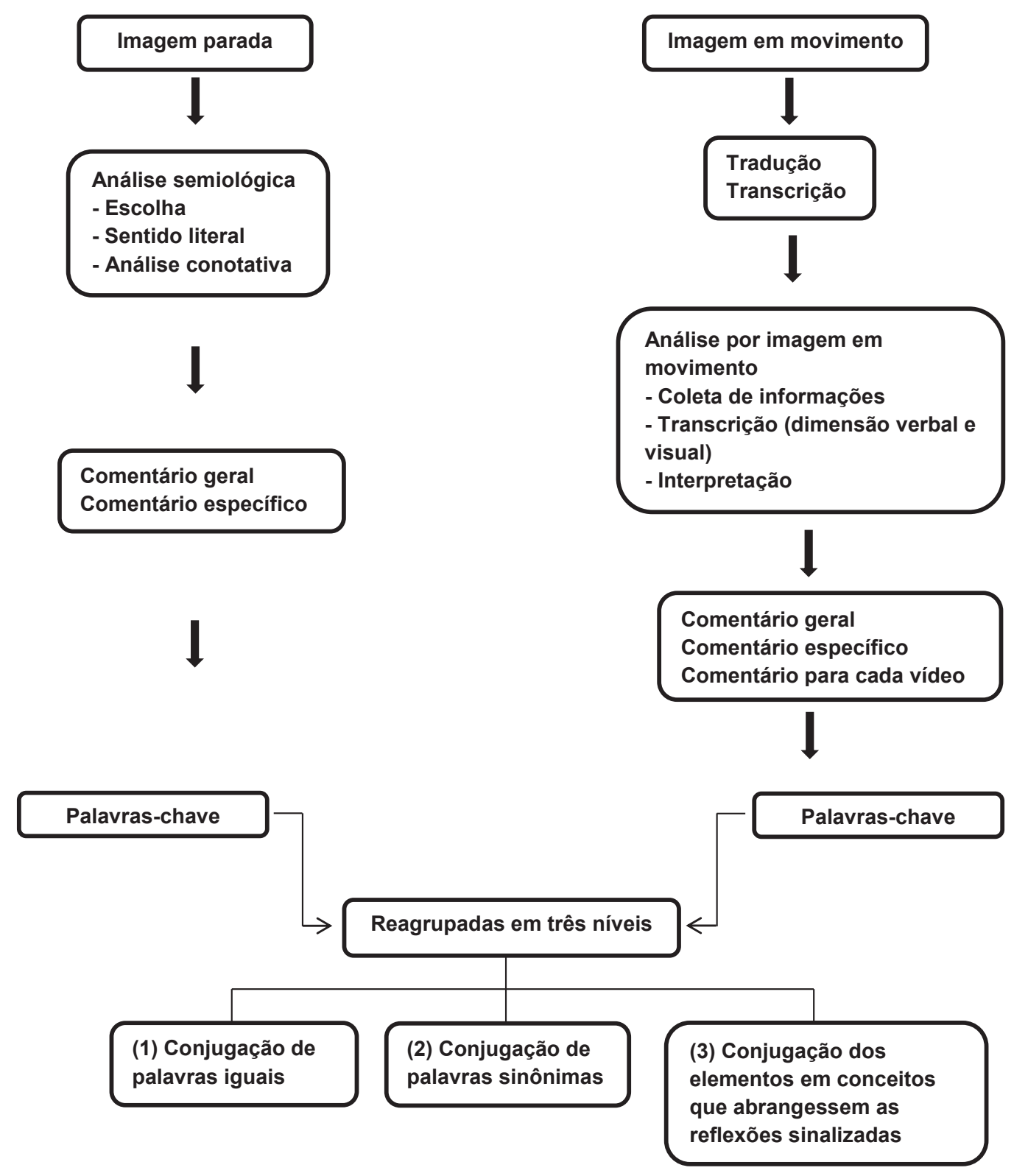

Fluxograma 1. Resumo do processo de análise imagética. 


\section{Resultados e discussão}

\section{Comer-dialogar: os ensinamentos de Jamie Oliver}

Jamie Oliver utiliza o Instagram para mostrar suas criações culinárias, contudo, não divulga apenas o seu trabalho, retrata também acontecimentos do cotidiano. Devido ao fato da dimensão visual exercer importante influência no ato alimentar, as fotos que contêm os belos resultados de receitas podem constituir estratégia para que as pessoas as executem: são um convite não verbal, útil, para incentivar hábitos saudáveis. As imagens postadas guardam um compromisso com a defesa que faz da alimentação saudável: saborosa e condizente com o ritmo de vida contemporâneo. Entretanto, os "seguidores" de Oliver não são apenas admiradores passivos das imagens produzidas

por ele. É interessante notar que as fotos também são, a propósito, uma maneira de interagir com o público, sendo idealizado, inclusive, um concurso de fotografias sobre alimentos. Este é um estímulo à criação e serve tanto para valorizar seu trabalho quanto dos participantes.

Por meio dos vídeos, é possível notar que Jamie demonstra interesse em ouvir o público, havendo um discurso que estimula o ouvinte a interagir com o cozinheiro e sua equipe por meio de comentários no Youtube. São exemplos:. "Continuem comentando", "claro, o canal é todo para você". "Então quanto mais você interage, mais nós faremos" e "temos escutado vocês. A propósito, Nós queremos mais! Mas nós realmente queremos chegar a algo agora. O tipo de respostas a todas as perguntas e preocupações sobre as receitas com as quais vocês estão lutando".

Nesse sentido, um pensamento chave percebido na abordagem de Oliver é a importância atribuída por ele ao diálogo e à escuta. Tal ideia é apoiada por Freire, ${ }^{11}$ quando afirma em sua obra Pedagogia da Autonomia: aquele que aprende a escutar para poder falar com, jamais fala impositivamente. Para este autor, o educador que escuta o aluno aprende a difícil lição de transformar o seu discurso em uma fala com ele.

O humor e a simpatia podem ser eleitos como traços de seu trabalho expressos tanto nos vídeos analisados quanto nas imagens. Em sua fala há um estímulo frequente para que as pessoas cozinhem apesar de/e considerando o pouco tempo de que dispõem. Contudo, Jamie e seus convidados propõem soluções viáveis, receitas que podem auxiliar nessa tarefa. As preparações são demonstradas como sendo fáceis, prezando-se por ingredientes naturais. Consideram também a região em que a pessoa reside e enfatizam a cultura alimentar própria de alguns locais.

b "Keep commenting", "of course the channel is all about you". "So the more you interact the more we'll do." "We've been listening to you and we want more by the way! But, we really want to come up with something now. The kind of answers all the questions and the worries about the recipes you're struggling with." 
Além desses comentários que tentam sintetizar as impressões deixadas sobre o trabalho de Oliver, o qual se preocupa em educar enquanto nutre, pode-se organizar os eixos que integram a sua prática profissional nas seguintes categorias: ele compreende que cozinhar é um ato político e contemporâneo e que expressa processos de singularização.

\section{Cozinhar é um ato político}

A política ligada à alimentação está expressa no próprio fato de Oliver estabelecer um posicionamento diante das questões relacionadas à alimentação, e faz isso em busca de um bem comum. É nesse sentido que seu trabalho é político, conforme Edgar Morin. ${ }^{12}$ Este autor aponta para um aspecto do referido conceito, encontrado no trabalho de Jamie Oliver: a formação de redes de convivialidade. Essas redes foram prejudicadas pela mercantilização generalizada, que desfez cooperações, solidariedades e bens comuns não monetários. A convivialidade compreende as cordialidades de pessoa a pessoa, a partilha e ainda a participação nas alegrias, prazeres e sofrimentos do outro. ${ }^{12}$

Oliver caminha nesse sentido ao incentivar Revolução (Revolution Day), uma transformação da alimentação em termos planetários, visando a um bem comum, que requer o empenho coletivo de pessoas organizadas em rede e que compreendam o alcance de sua ação. Assim, ainda que não organizado em um mesmo espaço geográfico, mas em redes sociais da internet, o Food Revolution Day pretende ser um manifesto, um dia de ação mundial, em que as pessoas são convidadas a se posicionarem em favor da comida de qualidade e do desenvolvimento de habilidades culinárias, rompendo com um padrão alimentar insatisfatório. É uma oportunidade para que se reúnam em suas casas, escolas, locais de trabalho e comunidade para compartilhar suas aptidões na cozinha, seus conhecimentos e recursos. Espera-se que o que encante os olhos alcance não apenas o estômago, mas a dimensão do pensamento, que gere reflexão. Objetiva-se que a comida boa para comer provoque o pensamento.

Revolution day parte do pressuposto do acesso universal: conscientizar as pessoas de que uma alimentação saudável e adequada é um direito humano. Desse modo, estão inclusos valores associados à preparação e ao consumo, pois a alimentação adequada implica a existência de atributos como acessibilidade física, financeira e cultural, sabor, variedade, cor, englobando o respeito a questões religiosas, étnicas e às peculiaridades dos diversos grupos e indivíduos. ${ }^{13}$ Aspectos esses percebidos nas ideias defendidas por Oliver e que chegam ao público na forma de discurso, o qual ganha materialidade na execução de sua receitas.

Assim como Jamie Oliver faz do espaço da alimentação um espaço político, a Educação Alimentar e Nutricional também deve estar interessada não apenas em garantir, por exemplo, o Direito Humano a uma Alimentação Adequada (DHAA), mas na formação de comensais que compreendam 
que comer é um direito. Nutricionistas que, ao deixar os bancos escolares, compreendam o porquê das políticas públicas que promovem o DHAA a partir de transferência de renda. Portanto, a ação por uma sociedade que busque no comer um bem comum e que se interesse pela reversão das iniquidades sociais em torno da alimentação se verte em política.

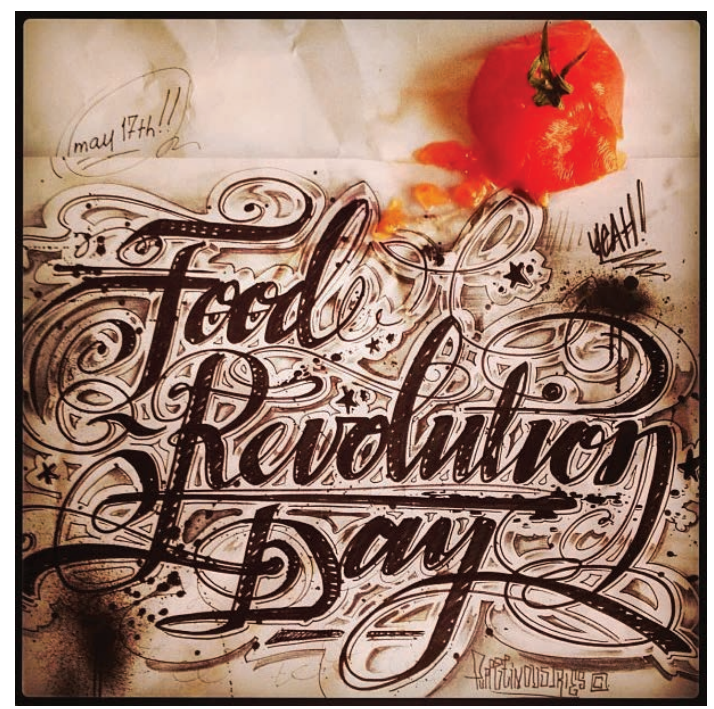

Figura 1. Food revolution day: 17 de maio é o dia de mobilização anual proposto por Jamie Oliver como manifesto por uma alimentação saudável e adequada.

Fonte: Instagram,imagem publicada em 20 de abril de 2013.

Além desse projeto de mobilização, o Fifteen também pode ser considerado um espaço de formação de rede de convivialidade in loco. Jamie acredita que a culinária, como habilidade própria do artífice, é um ofício que pode gerar emancipação econômica, social e cultural.

Fifteen é um restaurante com uma proposta de empresa solidária surgida no início dos anos 1990 que impulsionou a carreira de jovens desempregados ao ensinar-lhes a cozinhar. ${ }^{14}$ Além de se constituir em um meio de geração de renda, o trabalho do artífice é emancipador porque constrói a possibilidade do reconhecimento do artesão em seu objeto de criação. $\mathrm{O}$ artesão sente orgulho do resultado do seu trabalho, como Richard Sennett ${ }^{15}$ afirma.

Em análise do trabalho de Sennett, Bosi ${ }^{16}$ ressalta que o autor expõe a prática da repetição, feita de forma lenta e reflexiva, como a chave para alargar o conhecimento e também cultivar o prazer no trabalho. Esclarece, ainda, que um bom artífice é alguém que sabe o que faz, permanecendo 
no domínio de si mesmo. Logo, Jamie Oliver resgata a dimensão da culinária como via de transformação do sujeito e do mundo e não apenas como prática desprovida de pensamento. A ideia está apoiada pelo pensamento de Paulo Freire, ${ }^{11}$ quando fala que o educador, ao oferecer a ajuda necessária, deve contribuir positivamente para que o educando vá sendo o artífice de sua formação, apoiando-se no fazer-pensar sua prática.

Um dos resultados dessa visão é exibido pelo cozinheiro em um de seus vídeos. Ele apresenta Kerryann, uma das primeiras alunas no Fifteen, que é convidada ao seu canal no Youtube para participar, junto com ele e Gennaro Contaldo. Em outro momento a mesma ex-aluna, agora chef de cozinha, é convidada para executar um prato escolhido do livro de receita de sua família, o Easy Chicken Curry. A receita foi proposta pela jovem por se sentir reconhecida em uma preparação na qual participou da criação. Ela comenta:c "Este curry em especial é geralmente mais conhecido, na minha casa, como Kerryann porque é meu. Eu o inventei." Kerryann é também a protagonista de uma sessão de perguntas e respostas em outro vídeo no Foodtube.

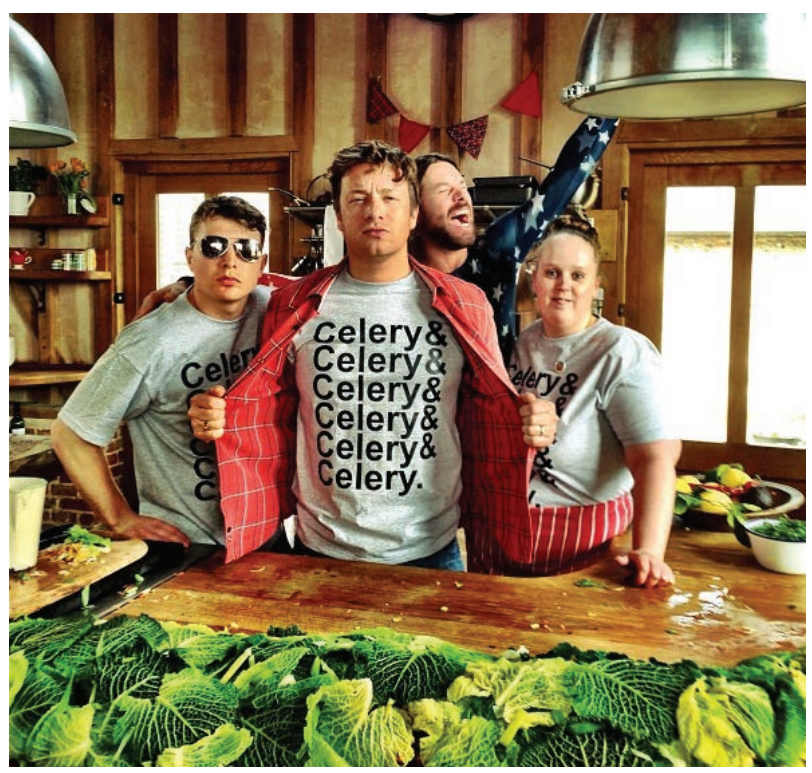

Figura 2. Transform-ação Fifteen: Kerryann à direita, cozinheira formada na escolarestaurante Fifteen.

Fonte: Instagram,imagem publicada em 11 de abril de 2013.

c “This particular curry is more commonly known, in my house, as a Kerriann. Because it's mine. I invented it." 


\section{Cozinhar é um ato contemporâneo}

Jamie Oliver é contemporâneo e compreende a alimentação como tal. O contemporâneo não coincide perfeitamente com o atual. Ele estabelece com o tempo uma relação de dissociação e anacronismo: "ele adere a este e, ao mesmo tempo, dele toma distâncias" para observar seus pontos cegos. ${ }^{17}$ Assim estabelece uma fratura cronológica, com o fim de promover um encontro entre tempos e gerações.

É nesse sentido que Oliver estabelece uma relação contemporânea com a alimentação: (1) tem um discurso e prática que aderem a este tempo, que o faz considerar o relevo da questão da praticidade na atualidade; mas (2) estabelece uma fratura e para descolá-la de seu próprio tempo, sublinha a importância do comer natural, fresco, equilibrado e variado. Suas intervenções como educador em alimentação repousam sobre tal imbricação.

Ao mostrar que a culinária saudável pode ser rápida, Jamie complementa a ideia de que cozinhar é um ato contemporâneo, porque se faz de mensagens apreendidas na obscuridade do tempo presente: onde tempo é dinheiro e não há tempo para nada. ${ }^{17}$ Jamie toma essa mensagem apreendida em terreno obscuro na atualidade e ousa ao provocar seus espectadores e convidados a desenvolverem receitas práticas - rápidas e simples - e saudáveis. Esta necessidade de adicionar rapidez ao preparo dos alimentos surge como uma alternativa para o comer saudável, contudo, incita uma reflexão sobre o ritmo de vida das pessoas na sociedade contemporânea. Nesse sentido, torna-se necessário distinguir rapidez da pressa. A primeira implica agilidade e atenção na tarefa de elaborar os pratos. Não exime, portanto, o criador de atuar com zelo. A pressa, contudo, induz ao descuido e precipitação.

Diez-Garcia ${ }^{18}$ trata da escassez de tempo para o preparo e consumo dos alimentos. Este é um dos aspectos da comensalidade contemporânea nomeados pela autora, somado à existência de produtos gerados com novas técnicas de conservação e de preparo; as várias opções de itens alimentares; deslocamentos das refeições de casa para estabelecimentos; a crescente oferta de preparações e utensílios etc. Tempo dos combos hiper e mega, mas com porções de tempo cada vez mais parcas. Onde fica nesse contexto cultural o tempo para o preparo e consumo de alimentos? Essa é uma das preocupações de Oliver e, também, um de seus focos de atuação.

Todavia, outrossim se faz necessária uma discussão para além do sujeito. Uma concepção de tempo constituída desta maneira em sociedade não pode ser combatida pelo sujeito individualmente. Problemas coletivos devem ser combatidos coletivamente. Como sociedade, e aí ganha novamente relevo o aspecto político do cozinhar e do comer, é essencial a empreitada pela criação de ambientes saudáveis que, por exemplo, possibilitem tempo para o preparo e consumo de refeições. A decisão de comer bem ou não e de dispor de tempo ou não para isso não se inscreve em um campo de decisão apenas micropolítico, mas macropolítico, no sentido de Guattari. ${ }^{19}$ 
Outro aspecto desta contemporaneidade é a culinária variada em porções adequadas, evocação constante nas fotografias, como pode ser observado na seguinte. Em uma sociedade que cultua o excesso, o super, o big, o extra, característica descrita por Claude Fischler como McDonaldização dos costumes alimentares, Oliver destaca preocupação com as quantidades no momento da organização dos pratos. ${ }^{20} \mathrm{O}$ cozinheiro localiza-se em seu tempo, mas se afasta dele para não cegar-se com suas luzes.

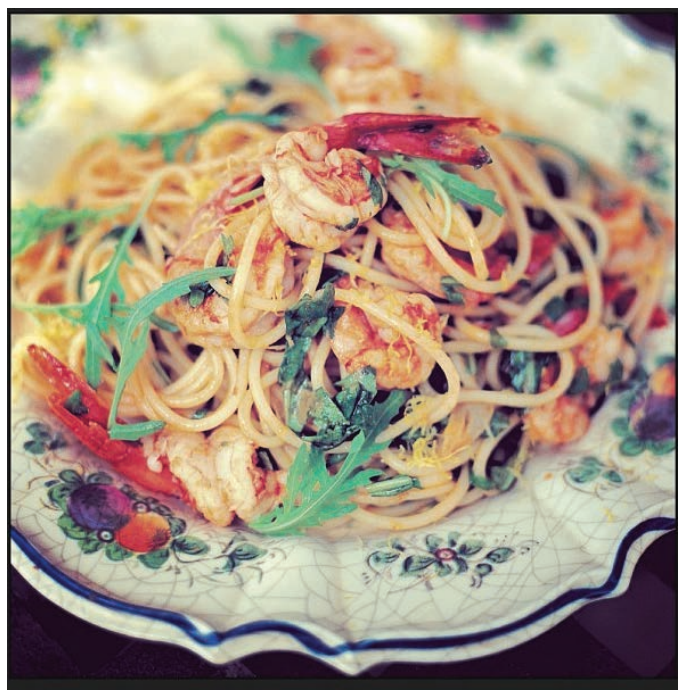

Figura 3. Alimentação como ato contemporâneo: fresca, natural, variada e prática.

Fonte: Instagram,imagem publicada em 30 de abril de 2013.

Diante das dietas monotemáticas, expressas em último grau pelas monoculturas alimentares, Jamie revela uma preocupação com a variedade. Do ponto de vista nutricional, a variedade alimentar é uma das garantias de uma dieta equilibrada por possibilitar o aporte necessário não apenas de macro como também de micronutrientes. ${ }^{2}$ Em uma perspectiva mais ampla, Oliver se expressa como focos de criatividade e resistência às monoculturas que dominam a atualidade: da mente, colonização do imaginário, ocidentalização do planeta, a civilização da beterraba, a mcdonaldização do mundo - expressões advindas de Vandana Shiva, Serge Latouche, Edgar Morin, Claude Lévi-Strauss, Maurice Holt. ${ }^{21}$

O fato de a culinária constituir-se patrimônio também é um manifesto de Oliver, que expressa a contemporaneidade do ato de cozinhar e comer, pois o contemporâneo revitaliza, re-evoca. ${ }^{17}$ Este 
pensamento é propagado em sentenças como "Eu não poderia deixar a Itália sem uma viagem à Costa de Amalfi, porque é de onde vem Gennaro, o chef que primeiro me ofereceu comida italiana”. O termo comida italiana remete à origem. O referido princípio parte, muitas vezes, da valorização do tradicional, do local, e resulta em atrair o paladar de pessoas, em muitos casos devido a um elo afetivo que possuem.

Conforme Santos,${ }^{22}$ os significados da alimentação, sejam eles históricos e/ou antropológicos, permitem captar traços da dinâmica cultural, fazendo com que a comida seja constitutiva do gosto de um grupo. Desse modo, a alimentação deve ser considerada patrimônio histórico gustativo de uma cultura, associada ao cotidiano dos indivíduos e dos grupos, e espaço de vida.

É interessante notar que no ato de alimentar-se há, de forma inerente, essa raiz que faz encontrar na cozinha algo além do nutritivo, um saldo de memória que se reativa cada vez que se come. ${ }^{23}$

Cozinhar expressa processos de singularização

Félix Guattari ${ }^{19}$ define os processos de singularização como uma forma de o sujeito se produzir que:

(1) não obedeça a um agenciamento serial, definido por uma sociedade capitalística que fabrica a produção do homem com o mundo e consigo mesmo. Por este motivo, tenta frustrar os modos originais e singulares de subjetivação, a reapropriação dos componentes heterogêneos de produção de subjetividade que emergem como reação ao processo geral de sua serialização. ${ }^{19}$ Os processos de singularização habilitam o sujeito a se reposicionar diante das questões postas, auxiliam na construção de linhas de fuga. Por isso, esta dimensão pode relacionar-se com um componente de expressão criativa.

(2) tampouco se refira a uma realidade psicologizante, privada de instâncias coletivas. Partindo da ideia de polifonia, proposta por Mikhail Bakhtine, Guattari aponta a subjetividade como plural e polifônica. Abarcando, em si, portanto, a heterogeneidade de sua produção, da qual participam instâncias individuais, coletivas e institucionais. E em determinadas situações a subjetividade se individua, em outras, torna-se coletiva, no sentido de se desenvolver para além do indivíduo, junto ao socius. Guattari ${ }^{19}$ afirma, portanto, que "a subjetividade individual resulta de um entrecruzamento de determinações coletivas de várias espécies, não só sociais, mas econômicas, tecnológicas, de mídia”.

Assim, a alimentação em Jamie Oliver expressa tais processos tanto ao favorecer o nascimento de uma política do comer, por estabelecer uma ruptura com o sistema capitalístico imposto, quanto, também, por favorecer a reapropriação de um sistema cultural alimentar ao sujeito, que passa

d "I couldn't leave Italy without a trip to the Amalfi Coast, because this is where Gennaro, the chef who first got me in to Italian food comes from." 
a compreender que alimentação, ainda que seja um processo que guarda fortes componentes individuais, instaura-se nas macro e micropolíticas de vida. Assim sendo, Oliver incentiva, sobretudo, como forma de invenção, a tomada do fazer culinário.

A prática de criação culinária é ativadora de processos de singularização. Esta se refere à autonomização do ser, de acordo com Guattari. ${ }^{24} \mathrm{~A}$ ideia envolve a capacidade de os grupos lerem sua própria situação e o que se passa em torno de si para se possibilitar a criação de novos modos de relação com o mundo e consigo mesmo, e desse modo, preservar a autonomia, o que ao final caracteriza a prática de autopoiese.

O fato de divulgar as fotos de suas obras culinárias em redes sociais pode ser considerado uma forma de demonstrar a autopoiese, a autoprodução, própria do artífice. As imagens estão impregnadas de criatividade, pois Jamie Oliver escolheu estabelecer uma relação de produção, de originalidade quanto à alimentação.

Diez-Garcia et al. ${ }^{2}$ corroboram a ideia acima ao afirmarem que a inclusão da culinária, como um exercício cotidiano, enquanto âmbito de trocas, parece ser propícia para intervenções de mudanças alimentares que habilitem a incluir a inovação e a reprodução das habilidades no manejo da comida. Inscrevem a prática da culinária como emancipatória.

A prática de singularização também repousa no princípio de que cozinhar e comer são modos de existir esteticamente, pois a estética tem esse caráter de ser produzida socialmente, ter determinações midiáticas e ser influenciada e influenciar a economia e tecnologia. ${ }^{19} \mathrm{O}$ cozinheiro, como artífice, é convidado a aproximar a mão da cabeça, ou seja, é convidado a pensar sua prática como forma de produção estética e questionar os padrões estabelecidos do bom, belo e do moderno. Assim sendo, em sua oficina, que é a cozinha, leva suas aptidões ao limite.

Jamie Oliver não dá o relevo ao estético tomado como simétrico, como se percebe no modo de produção hegemônico na atualidade e mesmo nos séculos XIV e XV, quando a estética da apresentação conduziu a surpreendentes montagens arquitetônicas de pratos. ${ }^{23}$ No trabalho de Oliver e sua equipe, a estética é qualidade do visual que é saudável e saboroso. Aspecto percebido em frases como as seguintes: "queremos picar algum coentro fresco. Estes talos estão encantadores; nós temos aqui uma boa pancetta listrada. Ela é realmente magra" e "Pimentões, um de cada cor. Algumas cebolas. Alho. Cenouras. Algumas batatas. Alguns cogumelos. Tomilho fresco e coentro". E segundo Le Breton, ${ }^{23}$ o gosto pela alimentação, a percepção do alimento na boca, é uma conjunção sensorial que mistura o aroma dos alimentos com sua tactilidade, sua temperatura, sua consistência, sua aparência, seu odor etc. Comer, então, é um ato sensorial total.

e "We want to chop some fresh coriander. The stalks are amazing; we've got here some nice streaky pancetta. It's really thin." "Peppers, one of each color. Some onions, garlic, carrots. Some potatoes. Some mushrooms. Some fresh thyme and some corriander." 
Contudo, a subjetividade, apesar de ser essencialmente social, é vivida e assumida por indivíduos em suas existências particulares. ${ }^{19}$ Este pensamento, que resgata os processos de singularização, distancia-se da ordem capitalística, a qual visa produzir os modos das relações humanas até em suas representações inconscientes: os modos como se trabalha, a relação com a natureza, com o corpo e com a própria alimentação. Desse modo, torna-se ainda mais oportuno o princípio de que cozinhar e comer são modos de estabelecer uma relação de intimidade, de proximidade com os alimentos. Esta afirmação está expressa em frases como as seguintes: "Você tem que fazer uma vez, duas vezes, então você vai construir a confiança para começar a adicionar coisas ou retirar coisas e colocar sua própria marca sobre ele, e em seguida, pode ser seu curry" e "tenho aqui um segredinho, isto aqui são pedaços de madeira de cerejeira. Isto é onde o flavor real vem para o seu BBQ/churrasco". Além disso, uma das imagens divulgadas mostra uma horta aparentemente cultivada em ambiente doméstico, o que sugere a referida intimidade.

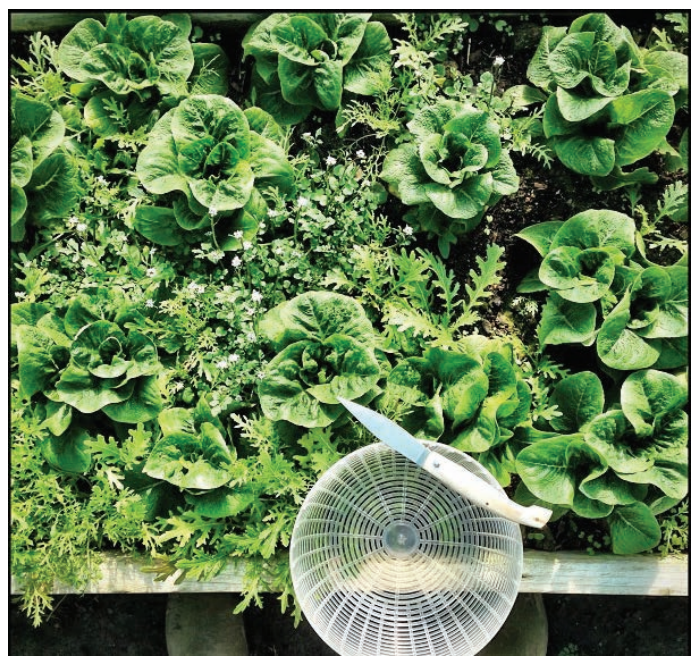

Figura 4. É da horta: preparação de alimentos com matérias colhidas de horta doméstica. Fonte: Instagram,imagem publicada em 13 de abril de 2013.

E, por último, o cozinheiro incita a prática social da comida, um modo de comer: a comida se constitui em uma celebração em comum, culminação festiva do laço social. ${ }^{23}$ Esta marca é observada também em momentos de Oliver com sua equipe de trabalho e sua família, presente em diferentes vídeos e fotos, como na seguinte.

f "Once you've made it a couple of times you will then build up the confidence to start adding your own things or taking things away and put in your own spin on it and then it can be your curry." "I've got a little secret for ya, these right here are cherry wood chunks. This is where the real flavor comes from for our BBQ." 


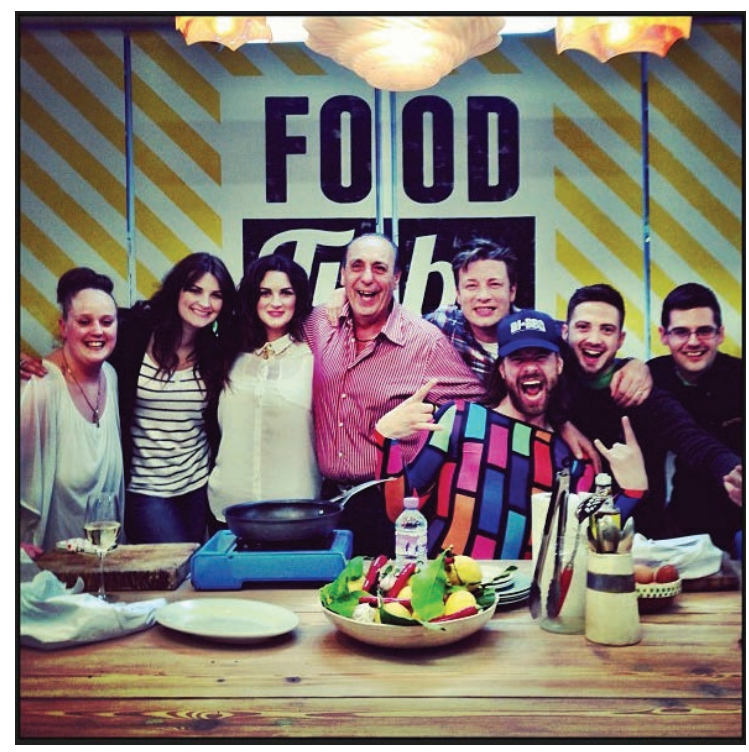

Figura 5. Comer é existir socialmente: comensalidade como via para singularização. Só o nós produz o eu.

Fonte: Instagram,imagem publicada em 22 de abril de 2013.

Os processos de singularização são uma maneira de romper com os modos de manipulação e modelização presentes no campo social, para construir outros modos de sensibilidade, de relação, de produção, de criatividade, capazes de singularizar a subjetividade. Logo, constituem um modo de afastar-se do achatamento para apropriar-se da produção da subjetividade. Comer, como atividade humana, guarda esta como uma das suas finalidades: a produção de uma subjetividade que enriqueça continuamente sua relação com o mundo. E é, sobretudo, pelo ato criativo que oferece a tomada do fazer culinário que o comensal pode deparar-se com os diversos matizes que sustentam a cultura alimentar: sua origem, sua prática, seus modos de partilha. É por este motivo que os processos de singularização tornam-se desveladores de um modo de produção que distancia o homem da matéria alimentar, serializando-a. ${ }^{24.25}$

\section{Conclusão}

Ao se lançar no ramo dos restaurantes, Oliver observou o tipo de refeições que predominavam nos estabelecimentos da Inglaterra. As repercussões negativas de uma alimentação inadequada na saúde das pessoas pelo mundo também o preocuparam. O cozinheiro começou a divulgar receitas 
como forma de contribuir para o estabelecimento de hábitos alimentares saudáveis, voltadas para todos os ciclos de vida.

Jamie Oliver é muito atuante na área de educação alimentar, desenvolvendo outros projetos que mantêm interface com ela além do já citado Food Revolution Day, que são: Jamiés Ministry Food e Jamie Oliver's Kitchen Garden Project.

Sobre o trabalho de Jamie, pode-se organizar os eixos que integram a sua prática profissional, enquanto cozinheiro que se preocupa em educar enquanto nutre, nas seguintes categorias: ele compreende que cozinhar é um ato político e contemporâneo e que expressa processos de singularização.

Quanto às demais ideias evocadas pelo trabalho de Jamie, vê-se que a comida mantém seu status de patrimônio, inclusive familiar. A alimentação, embora contemporânea, dialoga com aspectos atuais, acompanhando as mudanças na sociedade e pode se valer da culinária para veicular transformação de hábitos. A valorização da culinária enquanto prática emancipatória foi revelada na autopoiese e se reflete na importância do preparo do próprio alimento como constituinte do discurso de Oliver ao utilizar a culinária como meio para alimentação saudável, promovendo o autocuidado. O cozinheiro direciona seu discurso e projetos para gerar reflexões nas pessoas sobre o modo como se alimentam.

Aborda assuntos nutricionais de forma suave e divertida, sem moralizar as práticas alimentares que destoem de um padrão considerado saudável. Mas problematizando tais questões. Uma das ideias defendidas por Oliver, a comida saudável - entendida como nutricionalmente balanceada, variada e saborosa -, preparada de forma rápida, pode ser uma questão relevante para pensar a Educação Alimentar e Nutricional nos dias atuais. A interação com as pessoas, a valorização daquilo que elas produzem e expressam é um ponto interessante abordado por Jamie Oliver. Tais ideias podem contribuir para divulgar a Educação Alimentar e Nutricional de modo a envolver o público-alvo por instigar singularização.

O Marco sugere, pela amplitude da abrangência de EAN, que esta é uma prática multiprofissional e intersetorial. ${ }^{3}$ Ou seja, uma atividade de diálogo frequente entre nutricionistas, merendeiras, engenheiros agrícolas, agricultores, professores, cozinheiros, Ministério da Saúde, da Educação, da Agricultura, do Trabalho...

Uma atividade que, anteriormente, quando denominada educação nutricional, era privativa do nutricionista, ${ }^{g}$ hoje amplia seu escopo e convida outros profissionais a seu campo de abrangência. Inclusive, um chef de cozinha, educador da alimentação, que tem como desejo um movimento chamado food revolution: forte, sustentável, saboroso e inspirador. Bom apetite!

g Conforme Lei n. 8234/1991. 


\section{Referências}

1. Boog MCF. Educação em nutrição: integrando experiências. Campinas: Komedi; 2013. 268 p.

2. Diez-Garcia RW, Castro IRR. A culinária como objeto de estudo e de intervenção no campo da Alimentação e Nutrição. Ciênc Saúde Coletiva 2011; 16(1):91-98.

3. Brasil. Ministério do Desenvolvimento Social e Combate à Fome. Marco de referência de educação alimentar e nutricional para as políticas públicas. Brasília: MDS; 2012.

4. Castro IRR, Souza TSN, Maldonado LA, Caniné ES, Rotenberg S, Gugelmin SA. A culinária na promoção da alimentação saudável: delineamento e experimentação de método educativo dirigido a adolescentes e a profissionais das redes de saúde e de educação. Rev Nutr. 2007; 20(6):571-588.

5. Domingues J. Formação em gastronomia: Ingredientes e temperos de um profissional [dissertação]. Balneário Camboriú: Programa de Pós-graduação Stricto Sensu em Turismo e Hotelaria da Universidade do Vale do Itajaí; 2008.

6. Bettiol LW. A gastronomia e a comunicação: análise do discurso gastronomia a partir do chef Jamie Oliver e do filme Ratatouille [dissertação]. Brasília: Faculdade de Tecnologia e Ciências Sociais Aplicadas do Centro Universitário de Brasília; 2010.

7. Rodrigues RC. Análise e tematização da imagem fotográfica. Ci Inf. 2007; 36(3):67-76.

8. Sardelich ME. Leitura de imagens e cultura visual: desenredando conceitos para a prática educativa. Educar 2006; (27):203-219.

9. Bauer MW, Gaskell G. Pesquisa qualitativa com texto, imagem e som: um manual prático. 6. ed. Petrópolis: Vozes; 2007. 516 p.

10. Rose D. Análise de imagens em movimento. In: Bauer MW, Gaskell G. Pesquisa qualitativa com texto, imagem e som: um manual prático. 3. ed. Petrópolis: Vozes; 2003. Cap. 14.

11. Freire P. Pedagogia da autonomia: saberes necessários à prática educativa. 43. ed. Rio de Janeiro: Paz e Terra; 2011. 143 p.

12. Morin E. Política de civilização. In: Morin E. A via para o futuro da humanidade. Rio de Janeiro: Bertrand Brasil; 2013. p. 66-80.

13. Burity V, Franceschini T, Valente F, Recine E, Leão M, Carvalho MF. Direito humano à alimentação adequada no contexto da segurança alimentar e nutricional. Brasília: ABRANDH; 2010. 204 p.

14. Jamie Oliver Food Foudation. Here's how it started [Internet]. 2014. Disponível em: http://www. jamieoliver.com/the-fifteen-apprentice-programme/about/story

15. Sennett R. O artífice. 4. ed. Rio de Janeiro: Record; 2013. 360 p.

16. Bosi AP. O artífice. Estudos de sociologia [Internet] 2010; 15(28):291-294. Disponível em: http:// seer.fclar.unesp.br/estudos/article/view/2561/2181

17. Agamben G. O que é contemporâneo? In: Agamben G. O que é contemporâneo e outros ensaios. Chapecó: Argos; 2009. p. 56-73. 
18. Diez-Garcia RW. Reflexos da globalização na cultura alimentar: considerações sobre as mudanças na alimentação urbana. Rev. Nutr 2003; 16(4):483-492.

19. Guattari F, Rolnik S. Cultura: um conceito reacionário? In: Guattari F, Rolnik S. Micropolítica: cartografias do desejo. 11. ed. Petrópolis: Vozes; 2011. p. 15-39.

20. Fischler C. A 'McDonaldização’ dos costumes. In: Flandrin JL, Montanari M. História da alimentação. 2. ed. São Paulo: Estação Liberdade; 1998.

21. Brasil. Serviço Social do Comércio. Para um pensamento do sul: diálogos com Edgar Morin. Rio de Janeiro: SESC; 2011. 226 p.

22. Santos CRA. A comida como lugar de história: as dimensões do gosto. História: Questões \& Debates 2011; (54):103-124.

23. Le Breton D. El sabor del mundo: una antropologia de lós sentidos. Buenos Aires: Nueva Vision; 2007. 367 p.

24. Guattari F. Caosmose: um novo paradigma estético. São Paulo: Editora 34; 1992. 203 p.

25. Silva LA, Santos NIS. Subjetividade e trabalho na educação. Revista Mal-Estar e Subjetividades 2011; 11(4):1429-1460. 